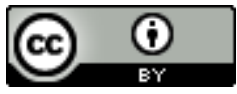

Esta obra está sob o direito de Licença Creative Commons Atribuição 4.0 Internacional.

\title{
CONTRIBUIÇÕES DA ATIVIDADE LÚDICA PARA O PROCESSO EDUCACIONAL
}

Sônia Lopes Sampaio Canelo ${ }^{1}$

Ana Cristina Lopes Sampaio ${ }^{2}$

Betijane Soares de Barros ${ }^{3}$

\section{RESUMO}

A atividade lúdica apresenta-se como instrumento transformador das práticas pedagógicas e como forte aliada no desenvolvimento do processo ensino-aprendizagem da criança e adolescente. A presente pesquisa busca responder à pergunta de como a atividade lúdica contribui com o processo ensino-aprendizagem. Considerou produções científicas publicadas entre 2015 e 2020, nos seguintes sites: BVS, Scielo e Periódicos da Capes. E, tem por objetivo analisar a influência da ludicidade como instrumento facilitador para ensino-aprendizagem. Tendo utilizado como metodologia a revisão sistemática, com a utilização de descritores estruturados no DeCS e MeSH. Os dados foram coletados no mês julho de 2020 e teve como critérios de inclusão artigos científicos pertinentes ao tema e como critérios de exclusão artigos científicos que não contemplam a temática ludicidade e processo educacional. Deste modo, a atividade lúdica, com todas as suas nuances, contribui significativamente para o processo educacional, sendo um instrumento facilitador da aprendizagem.

PALAVRAS-CHAVE: Atividade lúdica. Processo educacional. Ensino-aprendizagem.

\footnotetext{
1 sonialopessampaiocanelo@gmail.com

2 anacsampaio21@gmail.com

3 bj-sb@hotmail.com
} 


\section{INTRODUÇÃO}

$\mathrm{Na}$ construção dos complexos saberes típicos do ambiente escolar, o conjunto de conhecimentos alcançados por meio do lúdico era incompatível, pois o aprender demanda concentração e não combinava com brincar, rir e se divertir, considerados distração. Com o passar do tempo, o lúdico, o brincar passou a estar presente na vida social e cultural das pessoas. Apenas, atualmente, as atividades lúdicas passaram a ser consideradas como fator importante para o ensinoaprendizagem nas instituições escolares. A atividade lúdica apresenta-se como instrumento transformador das práticas pedagógicas e como forte aliada no desenvolvimento processo ensinoaprendizagem da criança e adolescente.

O processo educacional é efetivado respeitando vários fatores, como a idade do aluno, a prática pedagógica, entre outros,

\section{MÉTODO}

O método utilizado para elaboração da pesquisa foi a revisão sistemática, que obedeceu as etapas a seguir exposta no quadro 1, obedecendo alguns critérios como a exposição de do tema, objetivos e mas para que a aprendizagem de fato aconteça de forma eficiente é necessário entusiasmo. Assim, as práticas pedagógicas devem ser embasadas na dinamicidade através de atividades que proporcionem prazer e despertem o interesse (SOUSA et. al., 2018).

A atividade lúdica apresenta-se como resposta a essa dinamicidade da prática pedagógica e se destaca pela importância que tem para o desenvolvimento intelectual da criança e do adolescente, através de jogos e brincadeiras lúdicas com fim educativo, tendo no professor o mediador para fazer o lúdico acontecer da maneira correta a proporcionar o aprendizado (ROCHA; RIBEIRO, 2017).

A cultura lúdica proporciona referências que admitem a interpretação de jogos como atividades lúdicas e demonstram o potencial que os jogos e a recreação lúdica possuem dentro do processo educacional (FANTIN, 2015).

pergunta norteadora, além dos dados lógicos da pesquisa, sites e biblioteca acessados, descritores, string de busca e critérios de exclusão e inclusão dos artigos utilizados no presente artigo. 
Quadro 1 - Etapas da Revisão Sistemática.

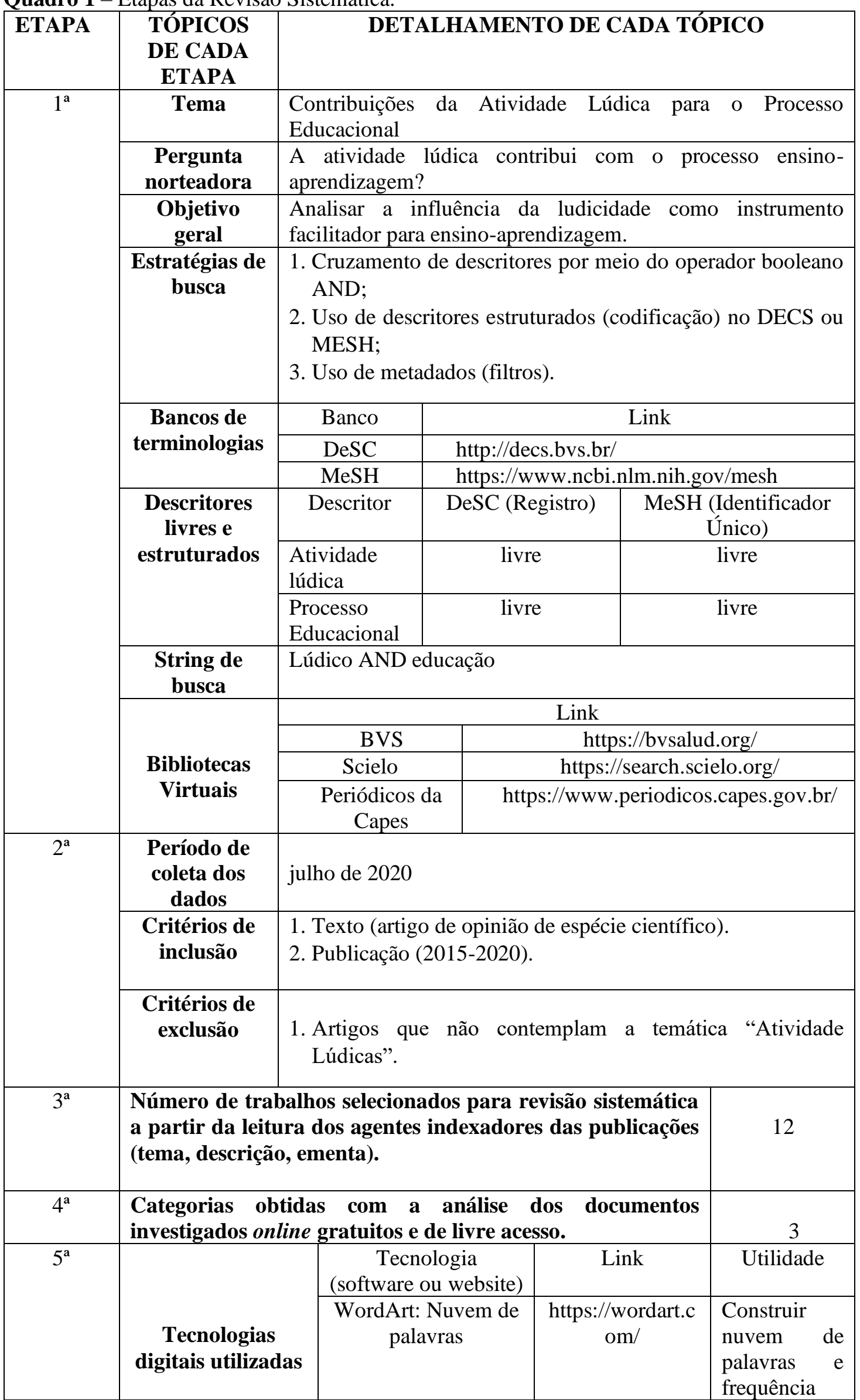




\begin{tabular}{|l|l|l|l|}
\hline & & & $\begin{array}{l}\text { das palavras- } \\
\text { chave para } \\
\text { criar as } \\
\text { categorias } \\
\text { temáticas. }\end{array}$ \\
\hline
\end{tabular}

Fonte: Elaborada pela autora.

\section{RESULTADOS}

Quadro 2 - Documentos disponíveis nas Plataforma BVS, Scielo e Periódicos da Capes, obtidos por string de busca.

\begin{tabular}{|c|c|c|c|c|}
\hline String de busca & $\begin{array}{c}\text { Bases de } \\
\text { dados } \\
\text { Plataforma }\end{array}$ & $\begin{array}{c}\text { Total de } \\
\text { publicações } \\
\text { sem o filtro }\end{array}$ & $\begin{array}{c}\text { Publicações } \\
\text { disponíveis } \\
\text { após aplicar } \\
\text { os filtros }\end{array}$ & $\begin{array}{c}\text { Publicações } \\
\text { aproveitadas na } \\
\text { Revisão } \\
\text { Sistemática }\end{array}$ \\
\hline \multirow{2}{*}{$\begin{array}{c}\text { lúdico AND } \\
\text { educação }\end{array}$} & BVS & 234 & 11 & 01 \\
\cline { 2 - 5 } & Scielo & 90 & 36 & 07 \\
\cline { 2 - 5 } & $\begin{array}{c}\text { Periódicos da } \\
\text { Capes }\end{array}$ & 831 & 38 & 04 \\
\cline { 2 - 5 } & TOTAL & 1155 & 85 & 12 \\
\hline
\end{tabular}

Fonte: Elaborada pela autora.

Foram detectadas 1.155 publicações

científicas nos bancos de dados, das quais 85 eram artigos disponíveis após o uso dos

filtros, desses foram feitos 12 downloads, que obedeceram aos critérios de inclusão, sendo submetidos às etapas da revisão sistemática.

Quadro 3 - Descrição dos artigos utilizados na pesquisa de acordo com os critérios de inclusão.

\begin{tabular}{|c|c|c|c|c|}
\hline $\mathrm{N}^{\circ}$ & AUTOR(A) & TEMA & ANO & RESUMO \\
\hline 1 & $\begin{array}{l}\text { Laís } \\
\text { Marconato } \\
\text { Corsi } \\
\text { Ademir De } \\
\text { Marco } \\
\text { Teresa } \\
\text { Ontañón }\end{array}$ & $\begin{array}{l}\text { Educação Física na } \\
\text { Educação Infantil: } \\
\text { proposta } \\
\text { interdisciplinar de } \\
\text { atividades circenses }\end{array}$ & 2018 & $\begin{array}{l}\text { Este estudo teve por objetivo estruturar } \\
\text { uma proposta pedagógica } \\
\text { interdisciplinar com foco no universo } \\
\text { circense, contemplando algumas de } \\
\text { suas atividades e aproximando a } \\
\text { educação infantil à arte, à cultura, ao } \\
\text { movimento, à expressão e ao lúdico. O } \\
\text { estudo consistiu em pesquisa } \\
\text { qualitativa, com caráter descritivo do } \\
\text { tipo documental, pois buscou } \\
\text { estabelecer relações baseadas em fontes } \\
\text { diversas. O texto apresenta } \\
\text { possibilidades de trabalho pedagógico } \\
\text { com as atividades circenses na } \\
\text { educação infantil, no intuito de } \\
\text { despertar para o planejamento } \\
\text { elaborado com aratégia } \\
\text { interdisciplinar, na qual participem } \\
\text { pedagogas, professores de Educação }\end{array}$ \\
\hline
\end{tabular}




\begin{tabular}{|c|c|c|c|c|}
\hline & & & & $\begin{array}{l}\text { Física e de demais áreas do } \\
\text { conhecimento humano que possam } \\
\text { contribuir com o desenvolvimento } \\
\text { integral das crianças participantes. }\end{array}$ \\
\hline 2 & $\begin{array}{l}\text { Andréia } \\
\text { Laísa } \\
\text { Cristina } \\
\text { Martins de } \\
\text { Sousa / Luiz } \\
\text { Fernando } \\
\text { Batista Loja / } \\
\text { Diego } \\
\text { Arantes } \\
\text { Teixeira } \\
\text { Pires }\end{array}$ & $\begin{array}{l}\text { Bingo Periódico: } \\
\text { atividade lúdica no } \\
\text { ensino de tabela } \\
\text { periódica }\end{array}$ & 2018 & $\begin{array}{l}\text { Nos últimos anos é crescente a } \\
\text { utilização de jogos no Ensino de } \\
\text { Química. Como a educação precisa } \\
\text { entusiasmar o ato de aprender no aluno } \\
\text { para que a aprendizagem seja mais } \\
\text { eficiente, se faz necessário, como, por } \\
\text { exemplo, a utilização de atividades } \\
\text { lúdicas em sala de aula. Os jogos } \\
\text { podem propiciar uma metodologia } \\
\text { inovadora e atraente no ensino, uma } \\
\text { forma mais prazerosa e interessante de } \\
\text { aprender, podendo tornar as aulas mais } \\
\text { dinâmicas, interessantes, divertidas e } \\
\text { facilitar o processo de ensino- } \\
\text { aprendizagem. Neste trabalho, } \\
\text { realizou-se o desenvolvimento de um, } \\
\text { jogo, denominado "Bingo Periódico". } \\
\text { O jogo foi desenvolvido em dois } \\
\text { formatos (digital e analógico) e aborda } \\
\text { o conteúdo de Tabela Periódica, } \\
\text { distribuição eletrônica e Diagrama de } \\
\text { Linus Pauling. A atividade lúdica } \\
\text { proposta foi aplicada e avaliada com } \\
\text { alunos do Ensino Médio e com alunos } \\
\text { do curso de Licenciatura em Química, } \\
\text { agradando a ambos os grupos e } \\
\text { mostrando-se uma boa alternativa para } \\
\text { a mediação de conteúdos relacionados } \\
\text { com o tema Tabela Periódica. }\end{array}$ \\
\hline 3 & $\begin{array}{lr}\text { Maria Silvia } \\
\text { Pinto de } \\
\text { Moura } \\
\text { Librandi da } \\
\text { Rocha } \\
\text { Rosangela } \\
\text { Benedita } \\
\text { Ribeiro }\end{array}$ & $\begin{array}{l}\text { Entre O Prescrito e } \\
\text { o Realizado: a } \\
\text { atividade lúdica no } \\
\text { ensino fundamental } \\
\text { de nove anos }\end{array}$ & 2017 & $\begin{array}{l}\text { O trabalho consiste na análise dos } 10 \\
\text { anos de experiência com a implantação } \\
\text { e implementação do Ensino } \\
\text { Fundamental de } 9 \text { Anos (EF9A) em } \\
\text { Itajubá, município do estado de Minas } \\
\text { Gerais, a fim de averiguar os modos } \\
\text { pelos quais políticas públicas são } \\
\text { implantadas e implementadas no Brasil. } \\
\text { A lei } 11.274 / 2006 \text { oficializou o EF9A } \\
\text { em âmbito nacional; resoluções, } \\
\text { relatórios e documentos orientadores } \\
\text { foram publicados e pesquisas } \\
\text { cientificas demonstram dificuldades em } \\
\text { efetivar as prescrições governamentais, } \\
\text { sobretudo em relação à inserção de } \\
\text { atividades lúdicas no currículo ofertado } \\
\text { ao } 1^{\circ} \text { ano. O material empírico se } \\
\text { constituiu por entrevistas } \\
\text { semiestruturadas com } 5 \text { Coordenadores } \\
\text { Pedagógicos, com diferentes tempos de } \\
\text { experiência com o EF9A, } \\
\text { perscrutando(i) a participação e }\end{array}$ \\
\hline
\end{tabular}




\begin{tabular}{|c|c|c|c|c|}
\hline & & & & $\begin{array}{l}\text { envolvimento dos entrevistados no } \\
\text { processo de ampliação do EF no } \\
\text { município, (ii) a construção do } \\
\text { currículo para o } 1^{\circ} \text { ano e (iii) } \\
\text { concepções e inserção da atividade } \\
\text { lúdica no cotidiano escolar. As análises } \\
\text { realizadas permitiram concluir que a } \\
\text { dificuldade em atender as leis e } \\
\text { prescrições deve-se à fragilidade } \\
\text { teórica, ao aligeiramento e } \\
\text { sobreposição de informações das } \\
\text { instâncias superiores. Espera-se que } \\
\text { essa pesquisa possa contribuir para a } \\
\text { revisão dos modos pelos quais novas } \\
\text { políticas públicas são implantadas e } \\
\text { implementadas no Brasil. }\end{array}$ \\
\hline 4 & $\begin{array}{l}\text { Ana Lúcia } \\
\text { Recalde de } \\
\text { Andrade }\end{array}$ & $\begin{array}{l}\text { O Brincar na } \\
\text { Educação Infantil }\end{array}$ & 2015 & $\begin{array}{l}\text { Este artigo analisou se a creche se } \\
\text { utiliza das brincadeiras no processo } \\
\text { ensino-aprendizagem e de como essa } \\
\text { atividade lúdica contribui para o } \\
\text { desenvolvimento e aprendizagem das } \\
\text { crianças. O estudo foi realizado na } \\
\text { Creche Municipal Neuza Nadir } \\
\text { Fuzinatto Graf, no município de Sinop, } \\
\text { Mato Grosso. A metodologia de } \\
\text { pesquisa foi a qualitativa, caracterizada } \\
\text { como estudo de caso, por meio de } \\
\text { observações na sala da turma creche II. } \\
\text { Após as observações e análise, como } \\
\text { resultados, a pesquisa mostrou que as } \\
\text { brincadeiras aliadas à demais atividades } \\
\text { na educação infantil, formam um } \\
\text { conjunto que produz conhecimento e } \\
\text { aprendizagem para as crianças. }\end{array}$ \\
\hline 5 & $\begin{array}{l}\text { Luciana } \\
\text { Martins } \\
\text { Quixadá / } \\
\text { Sylvie } \\
\text { Ghislaine } \\
\text { Delacours } \\
\text { Soares Lins / } \\
\text { Ana Carolina } \\
\text { Pontes } \\
\text { Tavares }\end{array}$ & & 2018 & $\begin{array}{l}\text { Visa-se problematizar sobre a formação } \\
\text { do leitor criança, no que se refere a uma } \\
\text { aprendizagem significativa da leitura, } \\
\text { considerando a brincadeira como um } \\
\text { meio para tal. Como autores centrais, } \\
\text { consultaram-se Vygotsky, Bakhtin e } \\
\text { Leontiev. Parte-se da compreensão de } \\
\text { que os processos desse tipo de } \\
\text { aprendizagem envolvem tanto a } \\
\text { atividade do aprendiz como também as } \\
\text { trocas discursivas que a permeiam. } \\
\text { Portanto, o ambiente escolar na } \\
\text { educação infantil deve promover } \\
\text { condiçôes de participação coletiva à } \\
\text { criança, por exemplo, pela via lúdica, } \\
\text { mediante as quais ela atue para } \\
\text { construir e atribuir sentido às novas } \\
\text { aprendizagens. Apresenta-se como as } \\
\text { crianças relacionam-se de maneira } \\
\text { lúdica com o livro a especial atenção } \\
\text { dada por elas ao "livro-jogo", através de }\end{array}$ \\
\hline
\end{tabular}




\begin{tabular}{|c|c|c|c|c|}
\hline & & & & $\begin{array}{l}\text { uma pesquisa realizada acerca do } \\
\text { acesso à literatura infantil em uma } \\
\text { escola pública da cidade de Fortaleza- } \\
\text { CE. }\end{array}$ \\
\hline 6 & $\begin{array}{l}\text { MONICA } \\
\text { FANTIN }\end{array}$ & $\begin{array}{l}\text { Crianças e Games } \\
\text { na Escola: entre } \\
\text { paisagens e práticas }\end{array}$ & 2015 & $\begin{array}{l}\text { O artigo situa algumas paisagens } \\
\text { teóricas e conceituais sobre os jogos } \\
\text { tradicionais, eletrônicos e digitais a } \\
\text { partir de referenciais dos estudos da } \\
\text { infância, dos jogos e da cultura lúdica. } \\
\text { Ao destacar as fronteiras que as } \\
\text { crianças ultrapassam quando integram } \\
\text { os diferentes informais e contextos } \\
\text { formais escolares, a diversidade que as } \\
\text { experiências com jogos propiciam às } \\
\text { com games a partir de outros modos de } \\
\text { ver a relação entre tecnologias e } \\
\text { crianças nos cenários da mídia- } \\
\text { educacãa. }\end{array}$ \\
\hline 7 & $\begin{array}{l}\text { Andrea } \\
\text { Perosa Saigh } \\
\text { Jurdi / Carla } \\
\text { Cilene } \\
\text { Baptista } \\
\text { Silva / Flavia } \\
\text { Liberman }\end{array}$ & $\begin{array}{l}\text { Inventários das } \\
\text { brincadeiras e do } \\
\text { brincar: ativando } \\
\text { uma memória dos } \\
\text { afetos }\end{array}$ & 2018 & $\begin{array}{l}\text { A unidade curricular ART - lúdico e } \\
\text { lazer tem por objetivo que o estudante } \\
\text { compreenda a importância das } \\
\text { atividades lúdicas e de lazer ao longo do } \\
\text { desenvolvimento humano e enquanto } \\
\text { recurso de intervenção profissional, } \\
\text { concebendo o brincar como legítimo } \\
\text { depositário da cultura de transmissão } \\
\text { oral de crianças, jovens, adultos e } \\
\text { idosos. Como docentes terapeutas } \\
\text { ocupacionais buscamos pensar e } \\
\text { aprofundar as metodologias utilizadas } \\
\text { nas aulas e suas ressonâncias para a } \\
\text { formação do Ser - terapeuta } \\
\text { ocupacional e para o conhecimento e } \\
\text { compreensão das populações por nós } \\
\text { acompanhadas. O uso de atividades na } \\
\text { formação de terapeutas ocupacionais é } \\
\text { uma premissa básica: fazer, construir, } \\
\text { ressignificar atividades e objetos, } \\
\text { recuperar. Porém, para além da } \\
\text { experimentação das atividades é } \\
\text { também competência do terapeuta } \\
\text { ocupacional saber como usá-las com a } \\
\text { população assistida por eles, } \\
\text { contextualizá-las e, principalmente, } \\
\text { inseri-las ou utilizar as atividades e } \\
\text { recursos que emergem da cultura de sua } \\
\text { população alvo. }\end{array}$ \\
\hline 8 & $\begin{array}{l}\text { Márcia } \\
\text { Mineiro } \\
\text { Cristina } \\
\text { D’Ávila }\end{array}$ & $\begin{array}{l}\text { Ludicidade: } \\
\text { compreensões } \\
\text { conceituais de pós- } \\
\text { graduandos em } \\
\text { educação }\end{array}$ & 2019 & $\begin{array}{l}\text { A ludicidade, presente no vocabulário } \\
\text { corriqueiro de muitas pessoas, é } \\
\text { compreendida simplesmente como } \\
\text { sinônimo de jogo, mormente ligada ao } \\
\text { universo infantil. Após aceder à } \\
\text { literatura, ao estudo e discussão } \\
\text { concernente à essa temática, podem } \\
\text { emergir significações de viés }\end{array}$ \\
\hline
\end{tabular}




\begin{tabular}{|c|c|c|c|c|}
\hline & & & & $\begin{array}{l}\text { acadêmico. O artigo apresenta } \\
\text { respostas à questão norteadora: quais } \\
\text { são as compreensões dos discentes, } \\
\text { pós-graduandos em educação, sobre a } \\
\text { ludicidade? Buscou-se aprofundamento } \\
\text { teórico em Luckesi (2014), Lopes } \\
\text { (2014) e Moraes (2014). O objetivo } \\
\text { geral é analisar as compreensões } \\
\text { conceituais sobre a ludicidade pelo } \\
\text { prisma dos discentes pós-graduandos } \\
\text { em educação. } \\
\text { especificamente: levantar o conceito de } \\
\text { ludicidade e seu campo semântico } \\
\text { construído pelos discentes; identificar } \\
\text { relações entre o lúdico e a educação; e } \\
\text { reconhecer as singularidades da } \\
\text { ludicidade e das atividades } \\
\text { potencialmente lúdicas sob o ponto de } \\
\text { vista discente. Justifica-se a } \\
\text { importância da temática pelas } \\
\text { contribuições teórico-práticas às } \\
\text { discussões acadêmicas em educação } \\
\text { sobre ludicidade no contexto do ensino } \\
\text { superior, enriquecendo a formação } \\
\text { profissional de docentes que se } \\
\text { proponham a mediar ludicamente. } \\
\text { Metodologicamente é um estudo de } \\
\text { caso qualitativo, junto aos discentes de } \\
\text { um componente curricular concernente } \\
\text { à ludicidade, oferecido em uma } \\
\text { instituição de ensino superior federal. } \\
\text { Os dados interpretados pela análise de } \\
\text { conteúdo são oriundos de fórum } \\
\text { eletrônico. Na interpretação, outras } \\
\text { fontes literárias ampliam a discussão: } \\
\text { Caillois (1990); Brougère (1998); } \\
\text { Huizinga (2000); Luckesi (2000); } \\
\text { Retondar (2007); Holzapfer (2003); } \\
\text { Kishimoto (2011) e D’Ávila e Leal } \\
\text { (2012). Entre outras conclusões, } \\
\text { levantou-se que o conceito lukesiano de } \\
\text { ludicidade como inteireza, plenitude e } \\
\text { estado subjetivo interno foi } \\
\text { internalizado e compreendido pelo } \\
\text { olhar discente. }\end{array}$ \\
\hline 9 & $\begin{array}{l}\text { Fernando } \\
\text { Teles } \\
\text { Larissa } \\
\text { Medeiros } \\
\text { Marinho dos } \\
\text { Santos / Cleci } \\
\text { Maraschim }\end{array}$ & $\begin{array}{l}\text { Um Game Para A } \\
\text { Psicologia Escolar: } \\
\text { proposições } \\
\text { teórico- } \\
\text { metodológicas para } \\
\text { a construção de um } \\
\text { artefato lúdico- } \\
\text { educativo }\end{array}$ & 2015 & $\begin{array}{l}\text { Este artigo apresenta proposições } \\
\text { teórico-metodológicas para o } \\
\text { desenvolvimento e o uso de um jogo } \\
\text { eletrônico educativo no âmbito da } \\
\text { formação do psicólogo escolar, como } \\
\text { objeto de uma investigação na área da } \\
\text { Informática na Educação. Como mais } \\
\text { um instrumento de aprendizagem, o } \\
\text { jogo poderá mediar negociações com a } \\
\text { Psicologia Escolar, estabelecendo uma }\end{array}$ \\
\hline
\end{tabular}




\begin{tabular}{|c|c|c|c|c|}
\hline & & & & $\begin{array}{l}\text { porta de entrada para esse campo de } \\
\text { estudos. Articulando as orientações da } \\
\text { Teoria Ator-Rede, a Teoria da Enação e } \\
\text { da Autopoiese, tecemos considerações } \\
\text { sobre como a aprendizagem mediada } \\
\text { por um game poderá dissolver } \\
\text { dicotomias como aluno-professor, } \\
\text { sujeito-objeto no ato de aprender e } \\
\text { ensinar. No intuito de passar ao largo da } \\
\text { prescrição didática no desenvolvimento } \\
\text { de um software educativo, refletimos } \\
\text { sobre a manutenção de uma posição } \\
\text { simétrica para o ato de conhecer com } \\
\text { base na proposta de uma epistemologia } \\
\text { política para o ensino e a pesquisa. }\end{array}$ \\
\hline 10 & $\begin{array}{l}\text { Rodrigo } \\
\text { Avila Colla }\end{array}$ & $\begin{array}{lr}\text { O brincar e } & \text { o } \\
\text { cuidado } & \text { nos } \\
\text { espaços } & \text { da } \\
\text { educação infantil: } \\
\text { desenvolvendo os } \\
\text { animais que somos }\end{array}$ & 2019 & $\begin{array}{l}\text { O presente artigo discute o brincar e o } \\
\text { cuidado como tarefas constitutivas do } \\
\text { desenvolvimento humano. Para tanto, } \\
\text { vale-se de contribuições teóricas de } \\
\text { autores que são referências na área de } \\
\text { educação infantil. A organização do } \\
\text { espaço, nessa etapa, e a } \\
\text { disponibilização de materiais } \\
\text { adequados também são tematizadas e } \\
\text { tratadas como práticas relevantes na } \\
\text { formação. O texto problematiza a } \\
\text { animalidade humana como um } \\
\text { conjunto de potências a serem } \\
\text { observadas nas crianças. Na proposta } \\
\text { aqui defendida, a pedagogia da primeira } \\
\text { infância deve estar atenta a tais } \\
\text { potências, bem como deve fomentar a } \\
\text { livre iniciativa das crianças, } \\
\text { propiciando condiços para que } \\
\text { realizem suas descobertas de modo } \\
\text { lúdico. Nesse processo, o cuidado } \\
\text { também é algo indispensável e consiste } \\
\text { na disposição dos animais que somos, } \\
\text { que é inextricável do ato de educar. }\end{array}$ \\
\hline 11 & $\begin{array}{l}\text { Íris } \text { Susana } \\
\text { Pires Pereira }\end{array}$ & $\begin{array}{lr}\text { O princípio } & \text { de } \\
\text { prática situada } & \text { na } \\
\text { aprendizagem } & \text { da } \\
\text { literacia: } & \text { a } \\
\text { perspectiva } & \text { dos } \\
\text { alunos } & \end{array}$ & 2017 & $\begin{array}{l}\text { O artigo resulta de uma investigação } \\
\text { realizada no âmbito de uma iniciativa } \\
\text { governamental destinada a melhorar os } \\
\text { níveis de literacia nas séries iniciais do } \\
\text { ensino fundamental em Portugal. A } \\
\text { investigadora estudou as } \\
\text { representações dos alunos sobre essa } \\
\text { experiência por meio da realização de } \\
\text { entrevistas em grupo. Este artigo } \\
\text { analisa os dados referentes às } \\
\text { representações dos alunos sobre uma } \\
\text { das dimensões pedagógicas centrais da } \\
\text { aprendizagem la da literacia, } \\
\text { nomeadamente a constituída pela } \\
\text { prática situada. A análise qualitativa } \\
\text { revela representacões muito positivas }\end{array}$ \\
\hline
\end{tabular}




\begin{tabular}{|c|c|c|c|c|}
\hline & & & & $\begin{array}{l}\text { sobre a prática que situou a } \\
\text { aprendizagem, tendo os alunos } \\
\text { expressado opiniões e sentimentos } \\
\text { extremamente favoráveis sobre a } \\
\text { prática de aprendizagem de literacia } \\
\text { que experimentaram. A análise dos } \\
\text { dados desvelou ainda que o contexto } \\
\text { que situou a aprendizagem foi ativo, } \\
\text { lúdico, colaborativo e mediado pelas } \\
\text { TIC. Esses resultados fundamentam, do } \\
\text { ponto de vista único dos próprios } \\
\text { aprendentes, uma redefinição do } \\
\text { entendimento atual do princípio da } \\
\text { prática situada da literacia nas séries } \\
\text { iniciais do ensino fundamental, no } \\
\text { sentido do reconhecimento da } \\
\text { centralidade da ludicidade nessa } \\
\text { aprendizagem. }\end{array}$ \\
\hline 12 & $\begin{array}{l}\text { Gilson Cruz } \\
\text { Junior }\end{array}$ & $\begin{array}{l}\text { Vivendo o jogo ou } \\
\text { jogando a vida? } \\
\text { Notas sobre jogos } \\
\text { (digitais) e } \\
\text { educação em meio à } \\
\text { cultura ludificada }\end{array}$ & 2017 & $\begin{array}{l}\text { Este artigo discute a ludificação da } \\
\text { cultura, evidencia e problematiza suas } \\
\text { implicações no que diz respeito às } \\
\text { relações entre jogos digitais e educação. } \\
\text { Para isso, orienta-se pelo seguinte } \\
\text { itinerário reflexivo: 1) a ludificação da } \\
\text { cultura como erosão do círculo mágico; } \\
\text { 2) a formação do sujeito no contexto do } \\
\text { século lúdico. }\end{array}$ \\
\hline
\end{tabular}

Fonte: Plataformas: BVS, Scielo, Periódicos da Capes, 2020.

O corpo textual foi avaliado por

meio da constância de palavras, que acarretou a nuvem de palavras - Figura 1 criada na Plataforma online WordArt. O
WordArt é uma ferramenta que agrupa e organiza graficamente as palavras-chave demonstrando aquelas mais frequentes.

Figura 1 - Nuvem de Palavras

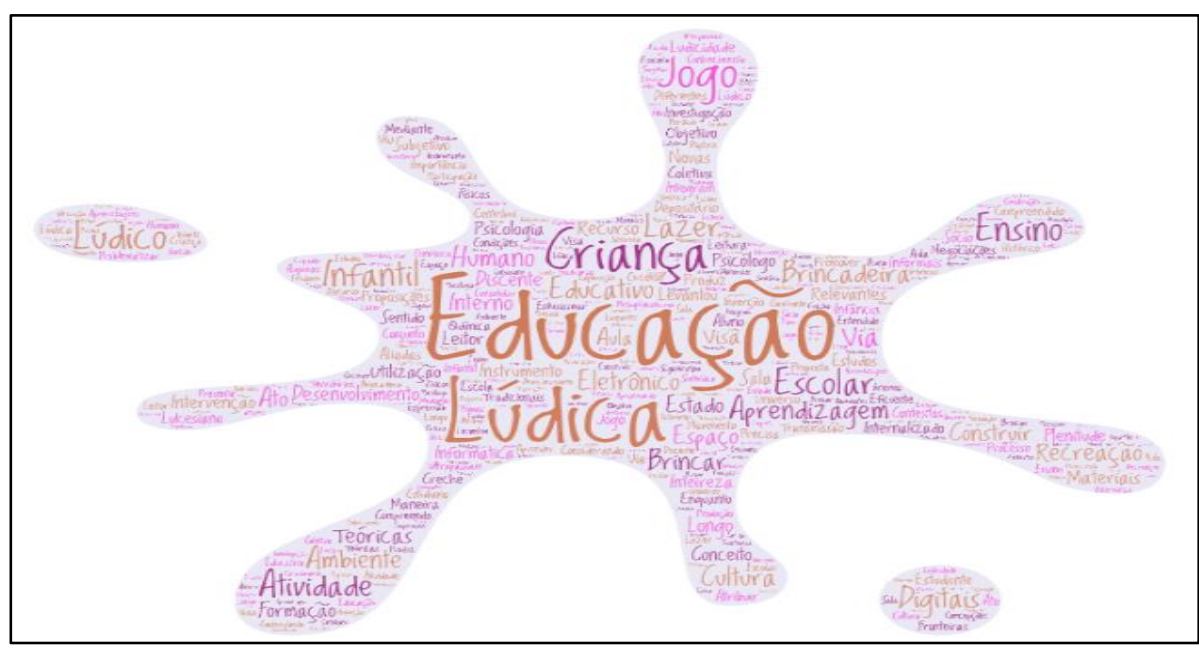

Fonte: Elaborada pelos autores. 
As categorias foram desenvolvidas com base na análise do conteúdo de Bardin, de acordo com as palavras que se destacaram na nuvem de palavras exposta na Figura 1, foi possível observar que as palavras em destaque na nuvem concernem as categorias desenvolvidas a partir da análise de conteúdo de Bardin. As categorias foram definidas levando em consideração a frequência que as palavras aparecem na nuvem de palavras e expostas na Tabela 1 abaixo, e que estão de acordo com o objetivo da pesquisa oferecendo relevância no contexto da ludicidade e 'processo educacional, conforme Quadro 2.

Tabela 1 - Frequência das palavras presentes nos textos publicados pelos artigos nas Plataformas: BVS, Scielo e Periódicos da Capes.

\begin{tabular}{|c|c|c|}
\hline PALAVRAS & FREQUÊNCIA & CATEGORIA \\
\hline Educação & 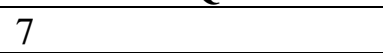 & \multirow{6}{*}{$\begin{array}{l}\text { O lúdico e a sua importância } \\
\text { para o processo educacional }\end{array}$} \\
\hline Lúdica & 7 & \\
\hline Criança & 7 & \\
\hline Aprendizagem & 6 & \\
\hline Atividade & 5 & \\
\hline Escolar & 5 & \\
\hline Jogo & 4 & \multirow{6}{*}{$\begin{array}{l}\text { A atividade lúdica como } \\
\text { instrumento facilitador para o } \\
\text { ensino-aprendizagem }\end{array}$} \\
\hline Infantil & 4 & \\
\hline Recreação & 3 & \\
\hline Lúdico & 3 & \\
\hline Brincadeira & 3 & \\
\hline Desenvolvimento & 3 & \\
\hline Educativo & 2 & \multirow{6}{*}{$\begin{array}{lcr}\text { Os jogos } & \text { educativos } & \text { e } \\
\text { recreação } & \text { lúdica } & \text { no } \\
\text { desenvolvimento } & \text { do } \\
\text { aprendizado } & & \end{array}$} \\
\hline Ambiente & 2 & \\
\hline Ensino & 2 & \\
\hline Eletrônico & 2 & \\
\hline Digitais & 2 & \\
\hline Brincar & 2 & \\
\hline
\end{tabular}

Fonte: Elaborada pela autora.

\section{DISCUSSÃO}

A ludicidade tem se apresentado como um instrumento, utilizado na prática pedagógica, facilitador do ensinoaprendizagem por apresentar conteúdos de forma divertida e prazerosa. Dentre as atividades lúdicas consideradas para $\mathrm{o}$ desenvolvimento da aprendizagem tem-se os jogos e as atividades recreativas lúdicas.

\section{O lúdico e a sua importância para o processo educacional}

O processo educativo é realizado por fases que englobam vários fatores, como a idade do aluno, a prática pedagógica, entre outros, e para que a aprendizagem de fato aconteça de forma eficiente é necessário entusiasmo. Assim, as práticas pedagógicas devem ser embasadas 
na dinamicidade "para que o pedagógico e o prático interajam de forma eficiente em todos os âmbitos educacionais" (SOUSA et. al., 2018).

Essa dinâmica que deve envolver a prática pedagógica de modo a facilitar a aprendizagem possui como principal ferramenta o emprego de atividades lúdicas, atividades essas, presentes no dia-a-dia da maioria dos jovens (SOUSA et. al., 2018).

Mas, o que significa o termo lúdico? É uma palavra de origem no latim ludus que remete para jogos e divertimento, ou seja, significa brincar (SOUSA et. al., 2018). Tal afirmação aplicada a prática pedagógica remete a ideia de aprender brincando, o que com certeza facilita o aprendizado.

O conceito de ludicidade é mais abrangente e possui três dimensões, quais sejam, cultural, psicológica e pedagógica. Cultural, pois as atividades lúdicas "são atos contextualmente sociais e relacionais". Psicológica, uma vez que envolve um estado de ânimo demonstrado através dos sentimentos. Pedagógica, “como princípio formativo e estruturante do processo de ensinar e aprender significativamente sem dicotomias entre pensar e sentir" (MINEIRO; D’ÁVILA, 2019).

A ludicidade tem permeado as novas estratégias pedagógicas para alcançar um ensino-aprendizagem mais eficaz e eficiente, de forma inovadora e prazerosa. $\mathrm{O}$ lúdico é um recurso didático que se encaixa perfeitamente nessas estratégias, por trazer a dinâmica para o ambiente escolar, que garantir efeitos positivos na educação, quando utilizado de maneira correta (SOUSA et. al., 2018).

A ludicidade deve estar presente em todo o processo educacional, mas é na educação infantil que o lúdico e a brincadeira deve prevalecer, já que nessa fase prevalece o mundo da fantasia e do faz de conta (CORSI et. Al., 2018).

A ludicidade é um método que auxilia o processo de ensino-aprendizagem, ou seja, contribui de forma significativa para o sucesso do processo educacional, no entanto, não consiste em um elemento estruturante do processo educativo, do reconhecimento da sua importância (MINEIRO; D’ÁVILA, 2019).

Muitas atividades podem ser desenvolvidas de forma lúdica atraindo a atenção dos alunos e proporcionando prazer na aprendizagem, assim, o lúdico estar presente na contação de histórias, na leitura compartilhada, nos jogos, dentre tantas atividades que podem ser trabalhadas dentro da escola, que ocasionam momentos de liberação de prazer e de fantasia (QUIXADÁ et. Al., 2018).

Diante disto, os docentes podem e devem apropriasse de metodologias lúdicas no processo de ensino-aprendizagem, como, por exemplo, "a utilização da construção de fanzines, produção escrita a 
partir da 'leitura' de gravuras, adivinhações, jogos com letras" no ensino da linguagem escrita, isso irá "despertar a imaginação, ativar discursos e, consequentemente, favorecer a aprendizagem das crianças". As práticas lúdicas estão envoltas da forma discursiva, pois, para atividade lúdica ter o resultado desejado se faz necessário a mediação da brincadeira, dos jogos simbólicos que estimulam a criança procurar agir de acordo com as instruções e compreender as relações propostas pela cultura, atribuindo uma roupagem nova (QUIXADÁ et. Al., 2018).

Para a prática pedagógica lúdica funcionar como instrumento para aprendizagem é necessário compreender as mudanças que ocorreram no mundo e o contexto sociocultural no qual a criança ou adolescente está envolvida, vez que a criança de hoje e sua cultura lúdica é muito diferente das de antigamente, assim a atividade lúdica deve acompanhar tais mudanças e rupturas, ao passo que, também, deve recuperar algumas práticas que a educação clássica proporciona (JURDI et. Al., 2018).

“Aprender não é processar símbolos, mas experimentar o mundo e articular-se com ele" (TELES et. Al., 2015). E, é a ludicidade que proporciona esse "experimentar" que faz a aprendizagem ser prazerosa e eficiente, é o aprender brincando. Deste modo, é possível observar que o lúdico tem, sim, grande importância para o processo educacional, principalmente quando se trata da educação para crianças e adolescentes, mas que não se restringe somente a essa faixa etária.

\section{A atividade lúdica como instrumento facilitador para o ensino-aprendizagem}

"O lúdico é um estado de plenitude interno e subjetivo" (MINEIRO; D’ÁVILA, 2019). Diante deste conceito, é possível observar que uma atividade lúdica pode ter o efeito lúdico para uma pessoa e pode não ter esse efeito para outra pessoa, já que decorre de um estado de plenitude de cada indivíduo. $\mathrm{O}$ lúdico deve ser trabalhado de forma que haja o envolvimento do indivíduo, ficando claro que o indivíduo, apesar de atividade ser potencialmente lúdica, não se sentir lúdico (MINEIRO; D’ÁVILA, 2019).

A atividade lúdica é uma atividade que envolve entretenimento, proporciona prazer e está relacionada ao ato de brincar. Quando atrelamos isso ao processo de ensino, esse acontece de forma prazerosa e eficiente. Assim, o Governo Federal, em 2006, prestigiou a temática em uma de suas orientações: "Orientações para a inclusão da criança de seis anos de idade", a referida orientação trata os processos de desenvolvimento e de aprendizagem envolvidos no brincar como essenciais ao 
processo de aprendizagem (ROCHA; RIBEIRO, 2017).

Interessante observar, que a apesar do reconhecimento acima exposto sobre a atividade lúdica, inexiste uma linha norteadora de trabalho adequada para amparar práticas pedagógicas com características específicas para desenvolver junto às crianças, pois, é nessa fase que as crianças estão aptas para o desenvolvimento de capacidades e, principalmente, de funções psíquicas superiores, tais como: atenção, memorização, concentração, criatividade etc. (ROCHA; RIBEIRO, 2017).

A atividade lúdica, que se destaca pela importância que tem para $o$ desenvolvimento psíquico superior e para a construção de zonas de desenvolvimento próximo, é a brincadeira de faz de conta, especialmente pela dimensão imaginária que possui. Porquanto, justamente é a representação uma peça essencial para o aumento das propriedades intelectuais e psicológicas da criança, contribuindo, também, para a obtenção dos conhecimentos transmitidos na escola (ROCHA; RIBEIRO, 2017).
A educação lúdica possui um mediador que é o professor, pois é ele que faz a mediação relacionando o cognitivo e o afetivo, assim a aprendizagem é o resultado dessa vivência (MINEIRO; D’ÁVILA, 2019).
A dimensão relacional que está presente na ludicidade decorre da relação entre os indivíduos, do indivíduo com o meio ambiente ou do indivíduo com artefatos, sem essa conexão a ludicidade não ocorre. No processo de ensinoaprendizagem existe essa relação dimensional e quando vem acompanhada da ludicidade, o aprendizado é favorecido (MINEIRO; D’ÁVILA, 2019).

A obtenção do sucesso no processo de ensino-aprendizagem, principalmente nas series iniciais, vem entrelaçado com a presença da ludicidade, sendo a través do mundo lúdico - imaginário, brincadeiras, jogos - que a criança ou adolescente vai interagir, despertar o interesse e inovar, além de responder com eficiência ao ensino. O educador deve aproveitar o espaço e objetos que possui a disposição para trabalhar atividades lúdicas e contribuir para o desenvolvimento (COLLA, 2019).

\section{Os jogos educativos e a recreação lúdica no desenvolvimento do aprendizado}

Muitos estudiosos têm analisado o desenvolvimento do aprendizado, como Vygotsky, entre outros. O aprendizado faz parte do desenvolvimento do indivíduo, ou seja, é através do aprendizado que o ser humano desenvolve suas habilidades para a vida e durante a vida. Como instrumento facilitador do desenvolvimento da aprendizagem apresenta-se as atividades 
lúdicas e, dentre elas, se destacam os jogos e a recreação lúdica, pois são atividades que proporcionam desafios e estímulos que despertam no alunado a zona de desenvolvimento proximal. Os jogos são facilitadores da aprendizagem que auxiliam os alunos nesse processo de adquirir novos conhecimentos (SOUSA et. al., 2018).

Para que os jogos possam desempenhar a função de facilitador da aprendizagem, de modo significativo dentro da sala de aula, deve ser aplicado de maneira correta com objetivos definidos que se deseja alcançar, e para tanto a figura do professor possui fundamental importância na aplicação das atividades lúdicas (SOUSA et. al., 2018).

Assim, o prévio estabelecimento de regras claras e do conhecimento de todos os participantes do jogo colaboram para o desenvolvimento adequado da atividade lúdica, dando a mesma o caráter educacional (SOUSA et. al., 2018).

O jogo está incluso na lista de atividades lúdicas brincantes, pois trata-se, sim, de uma brincadeira. E, como atividade lúdica brincante também é uma atividade recreativa lúdica, respeitando os limites exigido para isso, além da diversão um objetivo traçado e regras claras e acordadas entre os participantes (COLLA, 2019).

$\mathrm{O}$ docente tem a incumbência de expor o objetivo que se deseja alcançar com a utilização do jogo, bem como, de ser o responsável pela organização e auxílio da atividade, direcionando os alunos para o aprendizado através do ato de participar e interagir no jogo (FIALHO, 2013).

A importância dos jogos dentro processo educacional e demais atividades recreativas lúdicas perpassa o aprendizado do aluno, porquanto proporciona ao professor um feedback de sua prática pedagógica podendo, a partir daí, aperfeiçoar sua prática educacional (SOUSA et. al., 2018).

É evidente a contribuição do jogo para o aprendizado significativo. O jogo é um instrumento que, também, pode ser utilizado como material didático e como meio de avalição da aprendizagem dos alunos. A aprendizagem significativa ocorrerá quando aluno puder relacionar conceitos anteriores com novos conceitos, por isso a tamanha importância do papel do professor como facilitador, como mediador, na utilização de jogos (MOREIRA, 2011).

Outras utilidades para os jogos podem ser mencionadas como, por exemplo, instrumento de avaliação, mediação de um novo conteúdo ou melhorar os relacionamentos interpessoais, sejam entre aluno-aluno ou professor-aluno (SOUSA et. al., 2018). 
Os jogos têm apresentado várias utilidades dentro processo educativo, não se resumindo apenas a memorização do conteúdo dado, tem objetivado estimular o raciocínio, a participação ativa e a reflexão, e com isso, construir e reconstruir conhecimentos (SOUSA et. al., 2018).

Assim, os jogos didáticos são excelentes alternativas para dinamizar as aulas, trazendo $\mathrm{o}$ aspecto lúdico $\mathrm{e}$ propiciando o aprendizado. Os jogos fazem parte de uma prática pedagógica que leva o aluno à exploração de sua criatividade, melhorando o estímulo e atraindo o interesse pelas aulas. É um novo mundo desafiador que se apresenta dentro da educação, com novas formas de organização de atividades e formas de avaliação (SOUSA et. al., 2018).

Aplicação dos jogos como mediadores de conteúdos deve envolver a prática pedagógica diária dentro da escola, e em especial, dentro da sala de aula, pois os jogos são entranhados de ludicidade e possuem características próprias que bem direcionados pelo professor podem tornar a tarefa do aprendizado muito prazeroso e interessante (SOUSA et. al., 2018).

A utilização do jogo como forma de avaliação, fugindo das formas tradicionais, causa menos estresse e pressão nos alunos, pois irão realizar uma avaliação brincando, através de um método divertido e prazeroso (SOUSA et. al., 2018).
Diante disto, os limites entre jogo e vida real tem se tornado cada vez menos distinguíveis, pois a cada dia os novos jogos e brincadeiras atuais oferecidas, também pelo mundo digital, tem reduzido esses limites (JUNIOR, 2017).

Dispor de uma cultura lúdica é ter referências que admitem a interpretação de jogos como atividades lúdicas, sendo que estes poderiam não ter essa mesma interpretação por outras pessoas (FANTIN, 2015).

A recreação lúdica pressupõe uma atividade divertida e prazerosa, ou seja, é o brincar. Na brincadeira a motivação lúdica está presente de início ao fim, durante todo o percurso da atividade e não só no resultado. A brincadeira é uma representação do mundo humano ao redor da criança, sendo uma atividade humana, desta forma a criança desenvolve seu aprendizado tendo consciência sobre o mundo em que vive mediante a prática lúdica do brincar (QUIXADÁ et. Al., 2018).

O sentido lúdico de cada brincadeira varia de acordo com a idade da criança, e é o dia a dia da criança que vai dar origem a imaginação, sendo a brincadeira uma representação do mundo real. A criança descobre no brincar de faz de conta, numa leitura narrativa ou jogos simbólicos, o universo das relações sociais, interpessoais e do indivíduo com os objetos (QUIXADÁ 
et. Al., 2018). "A metodologia da aprendizagem da leitura e da escrita pode, assim, ganhar a forma da brincadeira, proporcionando uma aprendizagem participativa e significativa" (QUIXADÁ et. Al., 2018).

A criança aprende a lidar com a realidade através da brincadeira, pois é com brincadeira que ela representará o mundo real e irá interagir coma as demais crianças (ANDRADE, 2015).

A participação do professor nas brincadeiras com seus alunos dentro da sala de aula é um fator estimulante para o aprendizado, principalmente na educação infantil, pois nessa fase as crianças gostam de imitar os adultos. Assim, a brincadeira proporciona desenvolvimento e a construção do conhecimento (ANDRADE, 2015).
"O brincar constitui-se em um sistema que integra a vida social dos indivíduos e faz parte do patrimônio lúdicocultural, traduzindo valores, costumes, formas de pensamento e ensinamentos" (JURDI et. Al., 2018). Nesse contexto, depreende-se que a atividade lúdica disponibiliza uma nova relação com a vida, gerando novos modelos de sociabilidade imbuídos pela amizade, pela cooperação e pela noção de responsabilidade coletiva (JURDI et. Al., 2018).

Deste modo, em um contexto sociocultural da aprendizagem de crianças é necessário compreender dentre suas atividades, que o brincar possui caráter fundamental, pois, a criança avança no seu desenvolvimento brincando (PEREIRA, 2017). 


\section{CONCLUSÃO}

No decorrer do presente trabalho, observamos que a ludicidade proporciona um "experimentar" que torna a aprendizagem prazerosa, interessante e que causa entusiasmo. É o famoso aprender brincando. Aonde a criança/adolescente, de modo divertido, desenvolve seus conhecimentos e avança no aprendizado. Daí, surge a necessidade de práticas pedagógicas dinâmicas que busquem através de atividades lúdicas atrair a atenção do aluno.

A atividade lúdica é aquela atividade que envolve entretenimento, proporciona prazer e está relacionada ao ato de brincar. A atividade lúdica é um instrumento facilitador para o ensinoaprendizagem, no qual há uma relação entre professor-aluno e aluno-aluno, fazendo com que sujeitos envolvimentos do processo educacional interajam, socializem e desenvolvam habilidades.

\section{REFERÊNCIAS}

ANDRADE, Ana Lúcia Recalde de. O Brincar na Educação Infantil. Revista Eventos Pedagógicos Desigualdade e Diversidade étnico-racial na educação infantil, v. 6, n. 4 (17. ed.), número regular, p. 34-43, nov./dez. 2015.

COLLA, Rodrigo Ávila. O brincar e o Cuidado nos Espaços da Educação Infantil:
Os jogos educativos e a recreação lúdica são atividades educativas lúdicas que contribuem significativamente no desenvolvimento do aprendizado, quando aplicadas corretamente, por este motivo a presença do professor que participa e orienta como um mediador nesse processo é tão importante.

Os jogos educativos contribuem não só para a apreensão dos conteúdos expostos em sala de aula de forma eficiente, mas, contribui também, para estimular o raciocínio, proporcionar uma participação ativa e a reflexão, construindo e reconstruindo conhecimentos, e vai além, podendo ser utilizado como forma de avaliação no ensino-aprendizagem.

Assim, a atividade lúdica, com todas as suas nuances, contribui significativamente para o processo educacional, sendo um instrumento facilitador da aprendizagem, principalmente, quando se trata da educação para crianças e adolescentes.

desenvolvendo os animais que somos. Rev. Bras. Estud. Pedagog., v. 100, n. 254, p. 111-126, Brasília, jan./abr. 2019.

CORSI, Laís Marconato; MARCO, Ademir de; ONTAÑÓN, Teresa. Educação Física na Educação Infantil: proposta interdisciplinar de atividades circenses. Pensar a Prática, v. 21, n. 4, Goiânia, out./dez. 2018. 
FANTIN, M. Crianças e Games na Escola: entre paisagens e práticas. Revista Latinoamericana de Ciencias Sociales, Niñez y Juventud, 13 (1), pp. 195-208, 2015.

JUNIOR, Gilson Cruz. Vivendo o jogo ou jogando a vida? Notas sobre jogos (digitais) e educação em meio à cultura ludificada. Revista Brasileira de Ciências do Esporte, 39(3), pp. 226-232, 2017.

JURDI, Andrea Perosa Saigh; SILVA, Carla Cilene Baptista; LIBERMAN, Flavia. Inventários das Brincadeiras e do Brincar: ativando uma memória dos afetos. Comunicação Saúde Educação, 22(65):603-8, 2018.

MINEIRO, Márcia; D’ÁVILA, Cristina. Ludicidade: compreensões conceituais de pós-graduandos em educação. Educ.

Pesqui., São Paulo, v. 45, 2019.

PEREIRA, Íris Susana Pires. O Princípio de Prática Situada na Aprendizagem da Literacia: a perspectiva dos alunos. Educ. Pesqui., v. 43, n. 2, p. 393-410, São Paulo, abr./jun., 2017.

QUIXADÁ, Luciana Martins; LINS, Sylvie Ghislaine Delacours Soares;
TAVARES, Ana Carolina Pontes. O Lúdico como Atividade Discursiva e como uma Via para a Formação do Leitor: teoria e relato de pesquisa em uma escola pública em Fortaleza-CE. Educação \& Formação, v. 3, n. 7, p. 182-199, Fortaleza, jan./abr. 2018.

ROCHA, Maria Silvia Pinto de Moura Librandi da; RIBEIRO, Rosangela Benedita. Entre o Prescrito e o Realizado: a atividade lúdica no ensino fundamental de nove anos. Educação: Teoria e Prática, v. 27, n. 55, p. 262-283, Rio Claro/SP, maio-agosto/2017.

SOUSA, Laísa Cristina Martins de; LOJA, Luiz Fernando Batista; PIRES, Diego Arantes Teixeira. Bingo periódico: atividade lúdica no ensino de tabela periódica. Revista Thema, V. 15, $\mathrm{n}^{\mathrm{o}} 04$, 2018.

TELES, Fernando; SANTOS, Larissa Medeiros Marinho dos; MARASCHIM, Cleci. Um Game para a Psicologia Escolar: proposições teórico-metodológicas para a construção de um artefato lúdicoeducativo. Educação em Revista, v. 31, n.01, p.249-275, Belo Horizonte, JaneiroMarço 2015. 